\title{
Influence of Non-metallic Inclusions on Corrosive Properties of Polar Steel
}

\author{
Ming Lit,2, Huajie Wu ${ }^{1 *}$ and Yanhui Sun ${ }^{1}$ \\ ${ }^{1}$ Collaborative Innovation Center of Steel Technology, University of Science and Technology Beijing, Beijing, China, \\ ${ }^{2}$ Research Institute, Nanjing Iron and Steel Co., Ltd., Nanjing, China
}

Polar steel requires excellent toughness and corrosion resistance for breaking icy surfaces in low-temperature seawater environments. In this study, the effect of inclusions on the corrosion resistance of polar steel was examined. In the experiments conducted, the composition and morphology of the inclusions in steel were controlled using different deoxidation methods during steel refining. The morphology and composition of the corrosion-resistant active inclusions were analyzed using scanning electron microscopy and energy dispersive spectroscopy. The corrosion resistance of polar steel was determined by measuring the saturation current density of the anodic dissolution of

OPEN ACCESS

Edited by: Jung-Wook Cho,

Pohang University of Science and Technology, South Korea

Reviewed by: Xiangliang Wan,

Wuhan University of Science and Technology, China Pavlo Maruschak,

Ternopil Ivan Puluj National Technical University, Ukraine

*Correspondence:

Huajie Wu

wuhuajie@ustb.edu.cn

Specialty section: This article was submitted to

Structural Materials,

a section of the journal

Frontiers in Materials

Received: 04 September 2020 Accepted: 03 March 2021

Published: 25 March 2021

Citation:

Li M, Wu H and Sun Y (2021) Influence of Non-metallic Inclusions on Corrosive Properties of Polar Steel.

Front. Mater. 8:602851.

doi: 10.3389/fmats.2021.602851 steel in a corrosive medium via an electrochemical method. The corrosion resistance under simulated seawater was also investigated under laboratory conditions. It was found that as the ratio of $\mathrm{Al} / \mathrm{Mg}$ approaches the stoichiometric composition of the spinel (2.3-2.5), the inclusions become less active; as the ratio increases further, the corrosionresistant activity increases due to the formation of $\mathrm{MgAl}_{2} \mathrm{O}_{4} \cdot \mathrm{CaO}$ complexes, leading to an increase in local stress around the inclusions. If steel is deoxidized with $\mathrm{Zr}-\mathrm{Ti}$, small $\mathrm{Zr}$-Ti complex oxides form in the steel, providing nucleation particles for the precipitation of spheroidized and uniformly distributed MnS. Therefore, steel deoxidized with Zr-Ti has better seawater corrosion resistance than Al-deoxidized steel.

Keywords: deoxidation methods, corrosion resistance, current density, inclusion control, polar steel

\section{INTRODUCTION}

Low-temperature steels, which are used as ice breakers, are required to exhibit high strength, high ductility, good low-temperature toughness, and good corrosion resistance to seawater. Studies have found that long-term service of the steel causes no significant changes in the cementite phase. The microstructural degradation, revealed through hardness measurements, exerts only slight effects under static tension. It was reported that values of the basic mechanical properties of the steel have not changed when compared with the emergency reserve values (Panin et al., 2017, 2019). Several studies have investigated the effect of the addition of $\mathrm{Zr}$ and $\mathrm{Al}$ as deoxidizers on the size, distribution, and composition of inclusions (Rodionova et al., 2005a,b; Li et al., 2016). Studies have also been conducted to explore the corrosion resistance mechanisms of different steels, including the composition of non-metallic inclusions and analysis of other structural features. Corrosion

Abbreviations: RH, Ruhrstahl Heraeus; ASTM E112, Standard Test Methods for Determining Average Grain Size; GOST, Russian National Standard. 
tests, including the study of corrosive non-metallic inclusions, electrochemical measurements, and dynamic corrosion tests that simulate operating conditions under marine conditions, have been performed. Furthermore, preliminary recommendations have been made to optimize the inclusion control technology to increase the corrosion resistance of rolled steel.

Some studies have investigated the pitting corrosion behaviors of carbon and manganese steels, which are widely used as structural materials in vessel and marine engineering. The pitting corrosion resistance of these steels is known to be mainly affected by their metallurgic factors. Rare earth elements were found to effectively globularize sulfide inclusions in cast steels. The addition of Ce to AISI 202 stainless steel improves the corrosion resistance of the steel, owing to the metamorphic inclusions and improvement of the electrode potential in the matrix. Furthermore, adding solid $\mathrm{Cu}$ solution into cast steels increases the electrode potential of the steel and improves its corrosion resistance (Rodionova et al., 2005a; Zinchenko et al., 2005; Cai and Li, 2015). Notably, the excellent corrosion resistance of steel can be attributed to its low carbon content, high alloy content $(\mathrm{Cu})$, and fine microstructure (Sun et al., 2013). Cu and Cr enrich and enhance the compactness of the rust layer (Luo and Bai, 2011; Chen et al., 2012). Although inclusions and microstructures have been extensively investigated, knowledge regarding the factors associated with metallurgical processing, such as the degree of deoxidization, is scarce. Therefore, in order to further explore the influence of non-metallic inclusions on the corrosion resistance of polar steel, this paper compares the corrosion resistance of steel produced using three different deoxidization processes in the steel refining process, discusses the types of inclusions that are beneficial to improve the corrosion resistance of steel, and proposes a description of its mechanism.

\section{MATERIALS AND METHODS}

\section{Materials}

The steel specimens were prepared in a 150-ton furnace, then hot rolled into plates of $30 \mathrm{~mm}$ thickness, and finally aircooled to room temperature at about $25^{\circ} \mathrm{C}$. The actual chemical compositions of different steels were analyzed using a Spectro Lab emission spectrometer. Table 1 lists the composition of three steel types with the different deoxidation processes used in this study. The refining deoxidation process of Steel 1 is a low-Al deoxidation process. $\mathrm{Si}-\mathrm{Mn}$ alloys and $\mathrm{Al}$ are typically added to eliminate oxygen. Furthermore, instead of adding $\mathrm{Al}$ at the ladle furnace, an $\mathrm{Al}$ wire was added at the final stage of the Ruhrstahl Heraeus ( $\mathrm{RH})$ degassing process. Then, Ca treatment was conducted for 2-3 min.

The refining deoxidation process of Steel 2 was conducted as follows. Si-Mn alloy was added to eliminate oxygen. Al was added at the ladle furnace. Oxygen was blown during the $\mathrm{RH}$ process to modify the inclusions. The conditions for this process are as follows: $50 \mathrm{~m}^{3}$ oxygen blowing and $\mathrm{RH}$ post-calcium treatment.

The refining deoxidation process of Steel 3 followed the $\mathrm{Zr}-$ Ti complex deoxidation control points. Free oxygen of 400$600 \mathrm{ppm}$ from steel was eliminated with the addition of Si-Mn. Al was not added during tapping. When the oxygen content in the molten steel was 20-60 ppm, Fe-Ti and Fe-Zr alloys were added to further eliminate the oxygen.

Table 2 and Figure 1 show the mechanical properties and macrostructure of the steels. $\mathrm{Zr}-\mathrm{Ti}$ compound deoxidation is beneficial for increasing the elongation of low alloy steel, and the yield strength and tensile strength are comparable to that of Al deoxidized steel. According to the ASTM E112 (Standard Test Methods for Determining Average Grain Size), the structure is a mixture of quasi-polygonal ferrite, perlite, and bainite, and the average grain size is $5.8 \mu \mathrm{m}$. The tensile test specimens were perpendicular to the rolling direction, the microstructure test samples were parallel to the rolling direction, and the direction of the other test samples was not limited. There were 23 samples used in all. It can be seen from the data presented in Figure 2 that the microhardness of the sample has a stable value (170-200 HV).

\section{Test Methods}

The corrosion resistance of the steel samples in this study was determined by measuring the saturation current density of their anodic dissolution in a corrosive medium via an electrochemical method (refer to CTO-00190242-001-2008 of Russian Corrosion Standard). A number of specimens with a dimension of $30 \mathrm{~mm} \times 10 \mathrm{~mm} \times 6 \mathrm{~mm}$ were cut from the 30 -mm-thick steel plates. The tests were performed by the potentiostatic aging of the samples in a three-electrode cell at a potential $E$ of $300 \mathrm{mV}$ in a $0.5 \mathrm{M} \mathrm{NaCl}$ solution at $25^{\circ} \mathrm{C}$ for $1 \mathrm{~h}$. The value of the saturation current density after aging was used to predict the corrosion resistance of steel under specific operating conditions.

The corrosion resistance of the samples under laboratory conditions was investigated by simulating a seawater operation (refer to GOST 9.911-89 of Russian National Standard). Three samples were selected for each type of steel and the dimensions of each sample were $100 \mathrm{~mm} \times 50 \mathrm{~mm} \times 5 \mathrm{~mm}$. The surface of each sample was polished with a grinder and then rinsed with a cleanser, alcohol, and acetone in turn. Figure 3 displays a schematic illustration of a seawater simulator that was manufactured by University of Science and Technology Beijing. The simulator contains a workbox and storage water tank. For performing the corrosion tests in a moving environment, a seawater simulator was installed to provide a flow of approximately $10 \mathrm{~m} / \mathrm{s}$ along the surface of the samples. The simulated seawater environment is the seawater environment under the tidal zone, in which the oxygen concentration is close to saturation. The oxygen concentration near saturation test was conducted in the bathymetric tidal zone for 5 days. An aqueous $3 \%$ solution of sodium chloride was used as the corrosive medium; this medium was saturated by bubbling oxygen through it throughout the course of the experiment.

Changes in the surface morphology and composition of the inclusions after the corrosion tests were analyzed using a field emission scanning electron microscope (FE-SEM, JEOL JSM-7100F). The elemental distributions of the inclusions were measured using energy dispersive spectrometry (EDS). An accelerating voltage of $30 \mathrm{kV}$ with a $10 \mathrm{nA}$ probe current and a working distance of $10 \mathrm{~mm}$ were used to obtain the 
TABLE 1 | Measured chemical composition of the steels (wt\%).

\begin{tabular}{|c|c|c|c|c|c|c|c|c|c|c|c|c|}
\hline No. & C & Mn & $\mathbf{P}$ & $s$ & Si & $\mathrm{Ni}$ & $\mathrm{Cr}$ & $\mathrm{Cu}$ & Alt & $\mathrm{Nb}$ & $\mathrm{Zr}$ & $\mathrm{Ti}$ \\
\hline 1 & 0.06 & 1.34 & 0.010 & 0.001 & 0.20 & 0.35 & 0.16 & 0.24 & 0.033 & 0.030 & - & \\
\hline 2 & 0.06 & 1.34 & 0.010 & 0.001 & 0.21 & 0.35 & 0.16 & 0.23 & 0.032 & 0.030 & - & \\
\hline 3 & 0.06 & 1.30 & 0.010 & 0.001 & 0.16 & 0.34 & 0.12 & 0.22 & 0.023 & 0.028 & 0.012 & 0.01 \\
\hline
\end{tabular}

TABLE 2 | Mechanical properties of the hot rolled steel plates.

\begin{tabular}{|c|c|c|c|c|}
\hline Steel No. & Yield strength, MPa & Tensile strength, MPa & Elongation, \% & Impact energy, $\mathrm{J}\left(-120^{\circ} \mathrm{C}\right)$ \\
\hline 1 & 545 & 635 & 30 & 152 \\
\hline 2 & 505 & 585 & 24 & 288 \\
\hline 3 & 520 & 605 & 35 & 308 \\
\hline
\end{tabular}
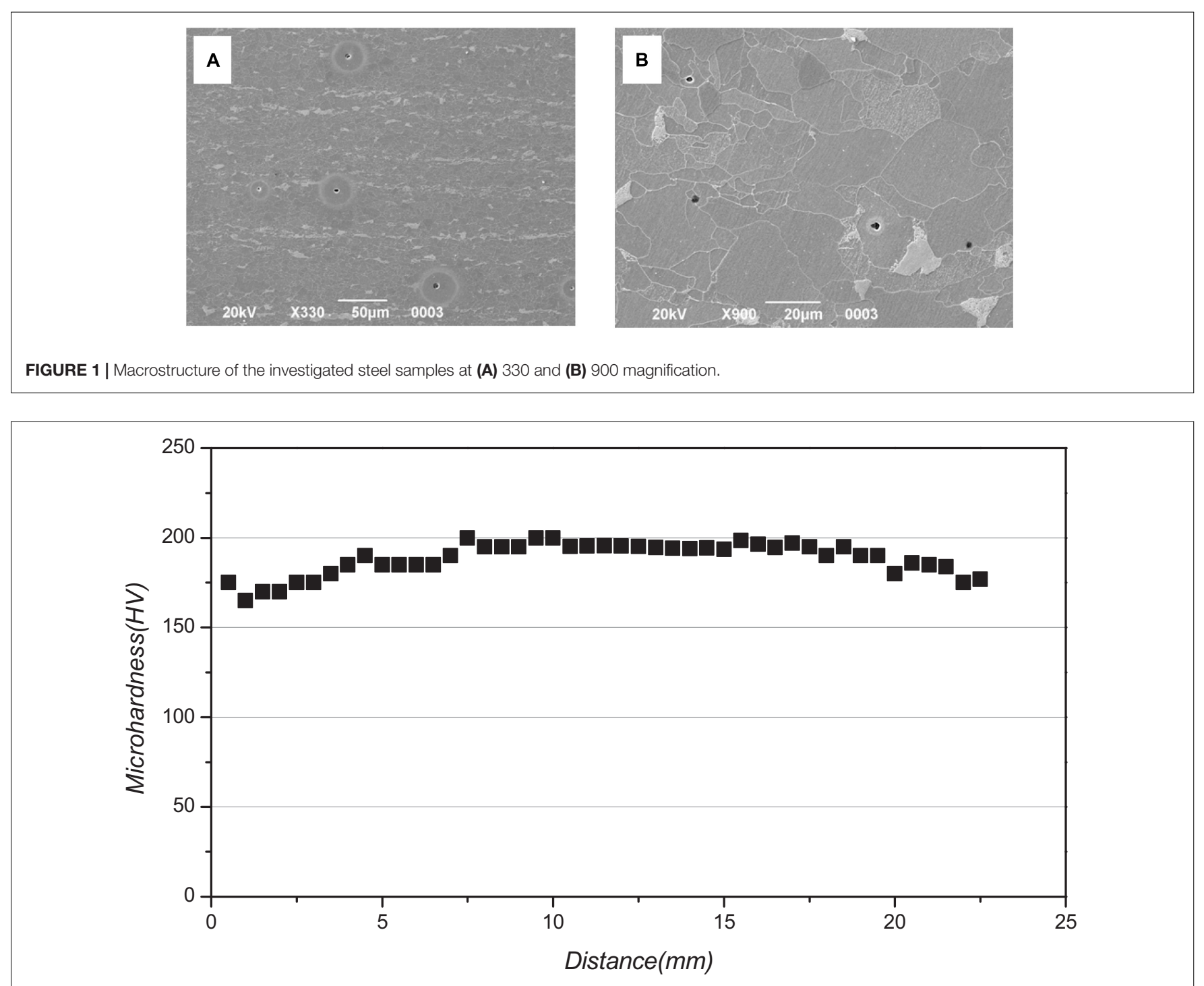

FIGURE 2 | Microhardness distribution of thickness direction in steel plate.

secondary electron images and conduct the EDS analysis. FESEM/EDS was also used to observe the morphology around the localized corrosion induced by the inclusions in the specimens.
The specimens used for microstructural analysis were prepared using the polishing machine SS-2000 Leco. The specimens were ground by a series of emery papers (up to grade 1200) and 


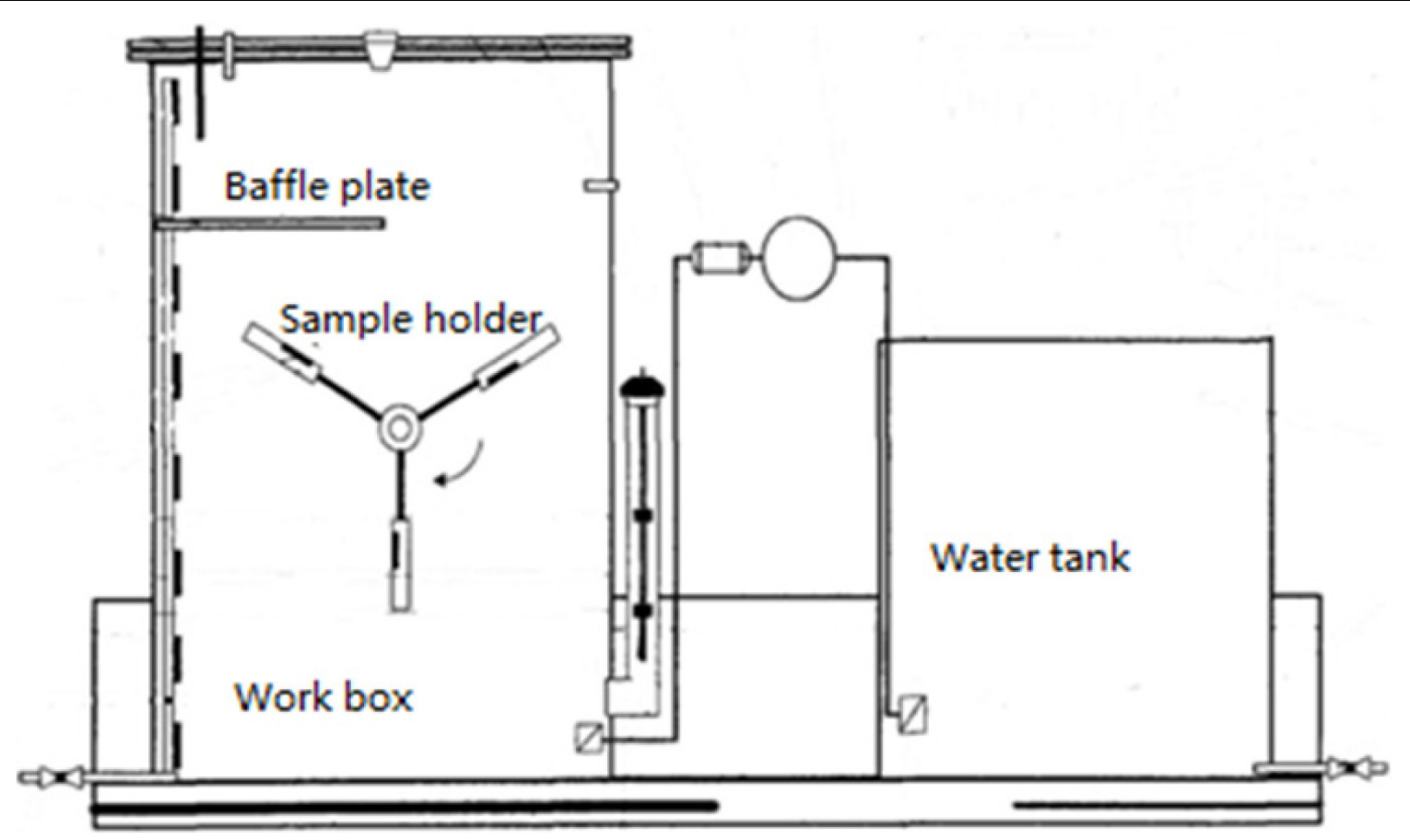

FIGURE 3 | Schematic illustration of a seawater simulator.

TABLE 3 | Density of the saturation current for the three steel samples.

\begin{tabular}{|c|c|c|c|c|c|}
\hline \multirow[t]{2}{*}{ Steel No. } & \multicolumn{4}{|c|}{$\mathrm{I}, \mathrm{mA} / \mathrm{cm}^{2}$ at $E=300 \mathrm{mV}$} & \multirow[t]{2}{*}{ Total (Ave) } \\
\hline & Measured (Top) & Ave (Top) & Measured (Bottom) & Ave (Bottom) & \\
\hline 1 & $6.71 / 6.27$ & 6.49 & $5.93 / 5.94$ & 5.93 & 6.21 \\
\hline 2 & $7.02 / 7.33$ & 7.17 & $7.17 / 6.96$ & 7.06 & 7.11 \\
\hline 3 & $6.45 / 6.60$ & 6.52 & $5.11 / 4.96$ & 5.03 & 5.78 \\
\hline
\end{tabular}

mechanically polished to a mirror view using aqueous diamond suspensions with particle sizes of $3 \mu \mathrm{m}$ and a fine silica suspension with particle sizes of $0.05 \mu \mathrm{m}$. The polished samples were degreased with ethanol.

\section{RESULTS}

\section{Corrosive Tests Using the Electrochemical Method}

Table 3 presents the corrosion resistance of the metals in terms of the saturation current density in the potentiostatic test. As indicated in the table, the corrosion current density of $\mathrm{Al}$ composite-deoxidized Steels 1 and 2 is greater than $6 \mathrm{~mA} / \mathrm{cm}^{2}$, while that of the $\mathrm{Zr}$-Ti-composite deoxidized Steel 3 is less than $6 \mathrm{~mA} / \mathrm{cm}^{2}$. Furthermore, the corrosion resistance of carbon steels in water increased with the addition of $0.10-0.16 \% \mathrm{Zr}$. This is attributed to the decreased anodic activity caused by the increase in the thermodynamic stability of the anodic phase or its passivation. During the cathodic process, $\mathrm{Zr}$ manifests itself through a large number of micro-cathodes, which do not affect the corrosion rate (Rodionova et al., 2004; Wei et al., 2020). Figure 4 shows the potentiostatic current versus time for the (A) 1 -specimen, and (B) 2-specimen in $0.5 \% \mathrm{NaCl}$ solution at $25^{\circ} \mathrm{C}$ with an applied potential of $E=300 \mathrm{mV}$. For the 2-specimen of Steel 3, substantially lower values were obtained for the saturation current density; this indicates their higher corrosion resistance. For the 2-specimen of Steel 3 with low levels of inclusion, the current density reaches its maximum value during the test and then does not change, while for Steel 2 with high contamination with inclusion, the current density continues to increase, which indicates an increase in the corrosion rate.

Notably, the inclusion density values within the same melting range and sample can vary. Steel 1 has a substantially lower saturation current density, indicating its higher corrosion resistance than Steel 2, which was contaminated with inclusion.

\section{Dynamic Corrosion Tests}

To compare the corrosion resistance of the three different steels contaminated with inclusions, dynamic corrosion tests were conducted in an environment with a seawater simulator. The results of the corrosion tests of the samples in a moving 

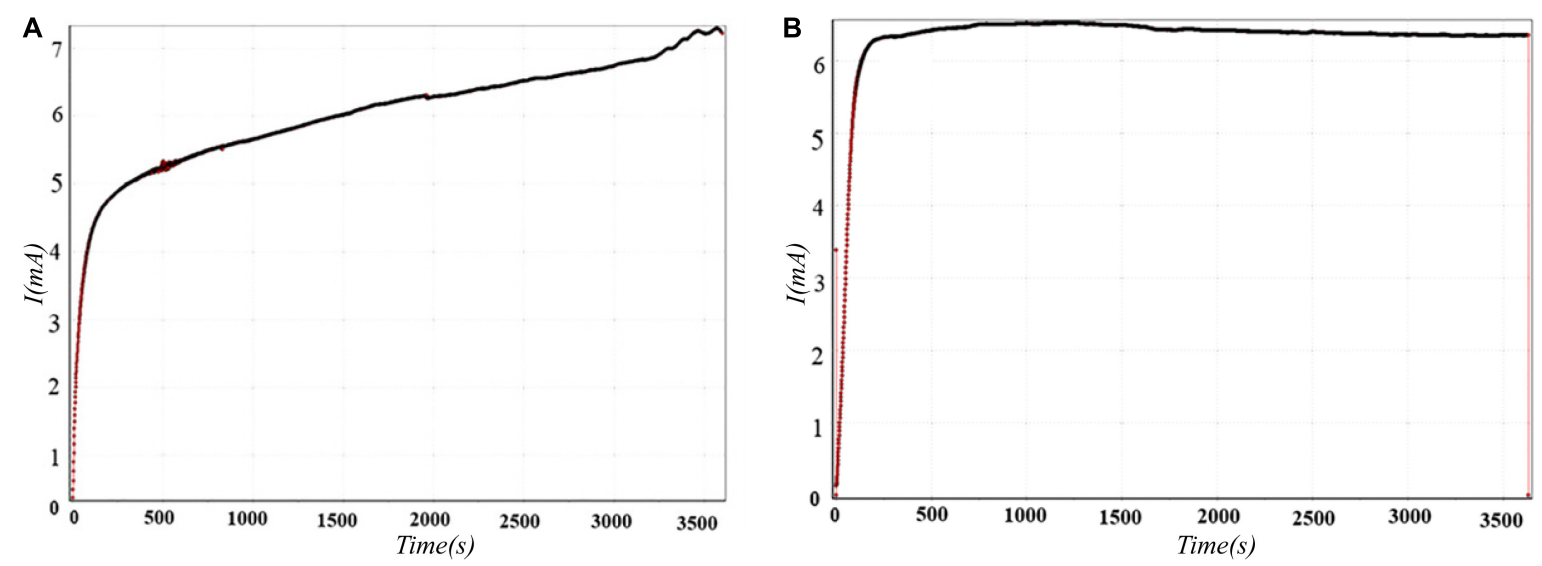

FIGURE 4 | Potentiostatic current (I) versus time (T) for the (A) 1-specimen and (B) 2 -specimen in $0.5 \% \mathrm{NaCl}$ solution at $25^{\circ} \mathrm{C}$ with an applied potential of $E=300 \mathrm{mV}$.

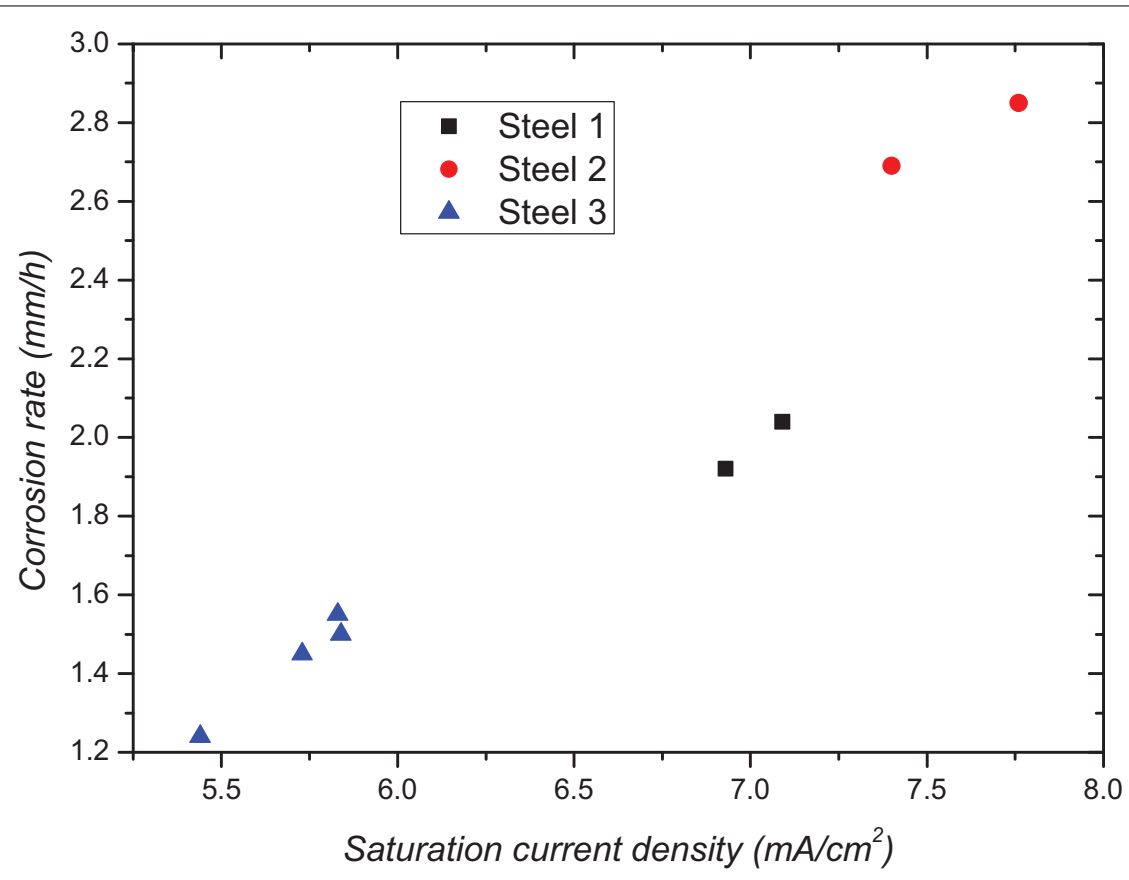

FIGURE 5 | Dependence of the corrosion rate on the saturation current density of the samples.

aqueous sodium chloride solution for $144 \mathrm{~h}$ are presented in Figure 5. During dynamic testing, the less contaminated side was considered as the work surface. For the analysis, the mean values for the saturation current density for both sides were measured as more corrosion processes were present during the dynamic tests than in the potentiostatic technique.

The average corrosion rate of the $\mathrm{Zr}$-Ti-deoxidized steel (Steel 3 ) is $48 \%$ lower than that of the Al-deoxidized Steel 2, and 27.27\% lower than that of the Al-deoxidized Steel 1. Thus, the $\mathrm{Zr}$-Ti-deoxidized steel exhibited a better seawater corrosion resistance. The increased $\mathrm{Ca}$ content in the oxide component of the inclusion resulted in its modification, thereby reducing the level of the arising stresses. The high ratio of $\mathrm{Al}$ to $\mathrm{Mg}$ in the oxide component of the inclusion and the absence of its modification with $\mathrm{Ca}$ could result in higher corrosive activity for the inclusions.

\section{Type, Morphology, and Composition of Inclusions}

Figure 6 presents the density and size of the inclusion of the three samples with different deoxidation processes. The inclusions in Steel 3, which underwent $\mathrm{Zr}-\mathrm{Ti}$ compound deoxidation, are in the range of 2-5 $\mu \mathrm{m}$. By contrast, the inclusions in Steel 2, which was strongly deoxidized by $\mathrm{Al}$, are relatively larger and distributed in the range of 5-20 $\mu \mathrm{m}$ with relatively fewer inclusions in the same area. Lastly, the inclusions in Steel 1, which was weakly 


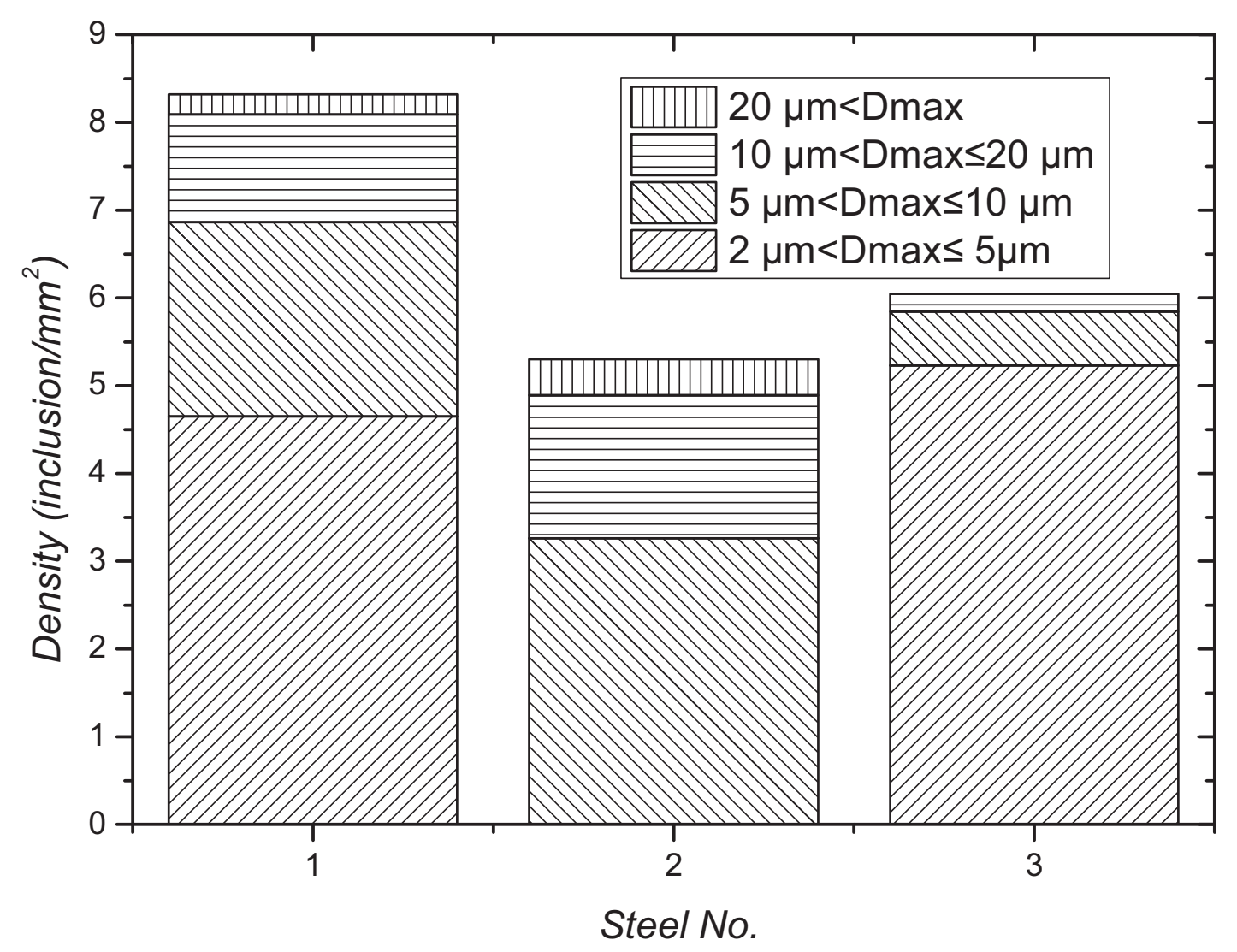

FIGURE 6 | Density and size of the inclusions in the samples.

deoxidized by $\mathrm{Al}$, are in the range of $2-20 \mu \mathrm{m}$ with most of the inclusions in the same area. Therefore, $\mathrm{Zr}$-Ti-deoxidized steel has a higher number of small inclusions than the Al-deoxidized steel.

The formation of small $\mathrm{Zr}$-Ti complex oxide inclusions in Steel 3 provides nucleation sites for the precipitation of $\mathrm{MnS}$, leading to the homogeneous distribution of small spherical $\mathrm{MnS}$ particles. Subsequently, this significant amount of MnS homogenizes the microstructure of the steel.

As seen in Figure 6, Steel 1 has a maximum contamination level of $8.3 \mathrm{incl} . / \mathrm{mm}^{2}$. In contrast, Steel 2 has the lowest inclusion contamination with the composition of its oxide component characterized by a high ratio and low calcium content. The micro-crevices and high-dislocation-density region around the inclusions can easily induce localized corrosion. Furthermore, inclusion clusters have a larger negative effect on the corrosion resistance of steel than single inclusions (Liu et al., 2018).

Figure 6 and Table 4 show the type and composition of the common inclusions found in the samples, respectively. The analysis of the results obtained by type, morphology, and chemical composition shows that the inclusions in the samples are liquids modified by calcium.

As presented in Figure 7 and Table 4, the inclusions in Steels 1 and 2 are characterized by the presence of calcium in the oxide component of the inclusions, which constitutes a significant portion of the inclusion; the average content of calcium was $5.2 \%$ and $2.5 \%$ in Steels 1 and 2, respectively. The average value of the $\mathrm{Al} / \mathrm{Mg}$ ratio determined in more than 10 inclusions for each sample was 4.5 and 5.3 in Steels 1 and 2, respectively. As the $\mathrm{Al} / \mathrm{Mg}$ ratio approaches the stoichiometric composition of the spinel (i.e., an $\mathrm{Al} / \mathrm{Mg}$ value of 2.3-2.5) and the calcium content increases, the inclusions become less active. Furthermore, as the $\mathrm{Al} / \mathrm{Mg}$ ratio increases, the corrosion activity of the inclusions increases, owing to the formation of complexes of the $\mathrm{MgAl}_{2} \mathrm{O}_{4} \cdot \mathrm{CaO}$ type; this leads to higher levels of stress in the matrix around the inclusion. Thus, a lower corrosion resistance of Steel 2 than that of Steel 1 can be attributed to both the largest amount of inclusion and their less favorable chemical composition.

Fine spherical (Al, rare earth)-oxy-sulfide inclusions were formed in rare-earth-bearing steel that was preferentially dissolved in the $0.5 \% \mathrm{NaCl}$ solution, which inhibited the propagation of the initial corrosion. In contrast, coarse $\mathrm{Al}_{2} \mathrm{O}_{3}$ inclusions were formed in the $\mathrm{Nb}$-bearing steel, thereby resulting in the selective dissolution of the $\mathrm{Fe}$ matrix and the further development of the initial corrosion (Zhang et al., 2019).

\section{Distribution of Elements Around the Inclusions}

A characteristic rift or halo around an inclusion can be attributed to several factors, such as the stresses in the matrix around the 
TABLE 4 | Chemical composition of the common inclusions found in the steel samples (wt\%).

\begin{tabular}{|c|c|c|c|c|c|c|c|c|c|c|}
\hline Steel No. & Spectrum & 0 & $\mathbf{M g}$ & Al & $\mathbf{S}$ & $\mathrm{Ca}$ & $\mathrm{Ti}$ & Mn & $\mathrm{Fe}$ & $\mathrm{Zr}$ \\
\hline 1 & 1 & 29.56 & 5.82 & 26.21 & 0.21 & 5.2 & 0.43 & 0.78 & 31.79 & - \\
\hline 2 & 1 & 48.53 & 6.91 & 36.49 & 1.23 & 2.50 & 1.48 & 1.16 & 1.70 & - \\
\hline 3 & 1 & 20.4 & 3.20 & 15.30 & 1.17 & 3.40 & 10.18 & 4.97 & 40.82 & 0.56 \\
\hline
\end{tabular}
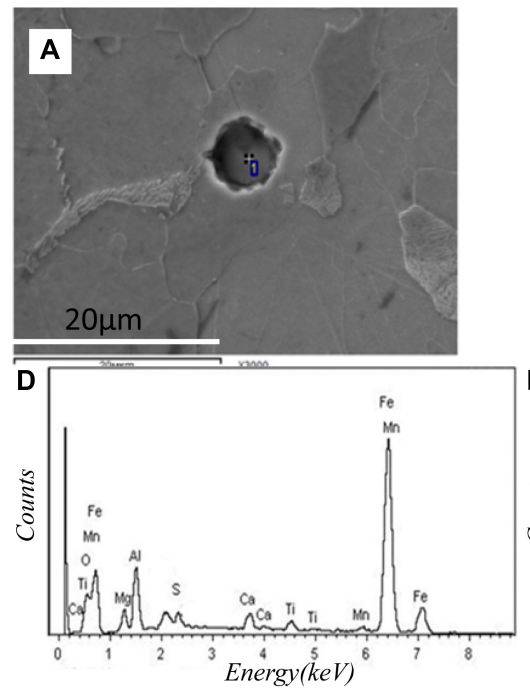
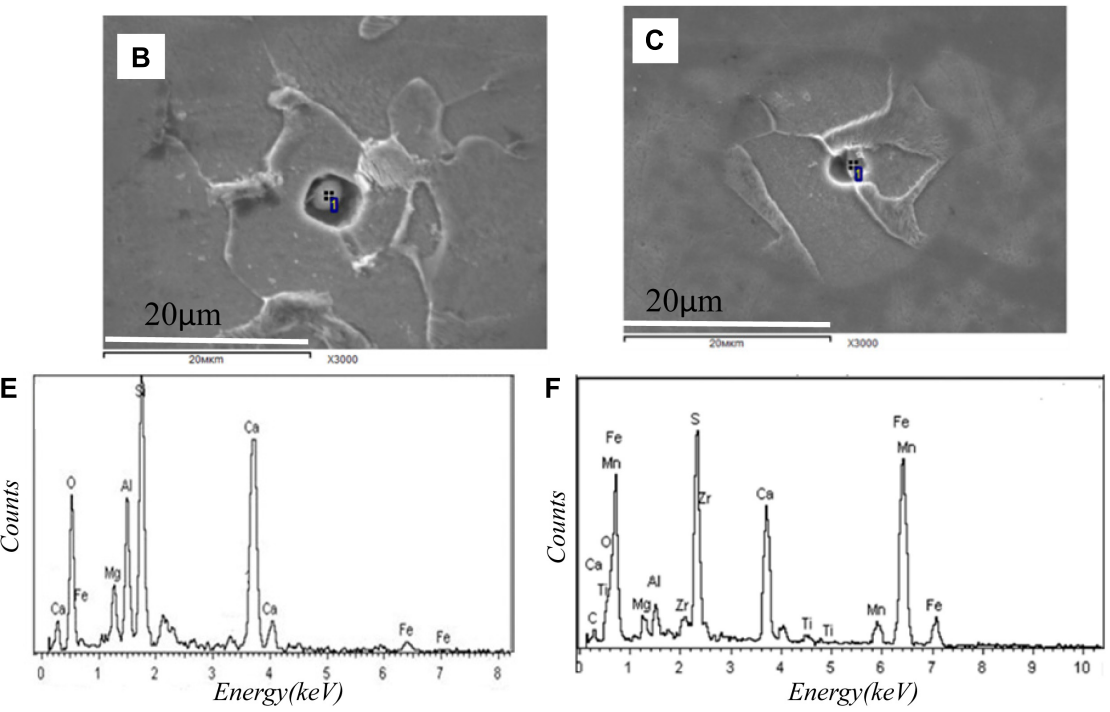

FIGURE 7 | (A-C) SEM images at 3000 magnification of (A) Steel 1, (B) Steel 2, and (C) Steel 3; (D-F) corresponding EDS spectra of the inclusions in the experimental steels, namely (D) Steel 1, (E) Steel 2, and (F) Steel 3.

inclusion that are caused by variations in the linear expansion factor of the matrix-inclusion. This can also be caused by the different chemical compositions of the matrix adjacent to the inclusion. Thus, the sections of the matrix around the inclusions were further investigated in terms of changes in their chemical compositions.

Figure 8 shows the distribution of the main elements near the inclusion, which differed from the rest of the matrix (C, Si, and $\mathrm{S}$ ) along a line passing through the region of the rifts around the inclusions to the more remote parts of the matrix. The chemical compositions were determined at separate points, spaced from each other at a distance of $0.5 \mu \mathrm{m}$.

The results presented in Figure $\mathbf{8}$ show that the rift region, which was limited by red lines on the figure, is characterized by an increase in the sulfur content, owing to the precipitation of the reaction products formed from the dissolution of the sulfide part of the inclusion immediately adjacent to the region. In addition, the region of the rift together with the non-etched area, which is the adjacent darker area (highlighted by the green lines with a radius of approximately $25 \mu \mathrm{m}$ ), is characterized by a reduced carbon and silicon content, compared with the more remote inclusion areas of the matrix. The heterogeneity of the chemical composition near the inclusion can be associated with the stresses arising in this region, resulting in the redistribution of the elements in a solid solution, including carbon and silicon. The dissolution of the inclusions, in turn, induced the electrochemical activity of pitting corrosion and further inhibited the propagation of local corrosion (Wei et al., 2020).
The effects of the various sizes of the MnS inclusions on the spring steel corrosion mechanism were also investigated. Severe corrosion occurs at the MnS inclusions with original micro-crevices (Shi et al., 2018). The sulfide inclusions in steel, which vary from short spindle-like to long strip-like shapes with an increasing degree of deoxidization, are considered as sites for pit nucleation. Under the same conditions, as this degree of deoxidization decreases, the pitting initiation susceptibility decreases, and the resistance to pit propagation is strengthened (Alfred et al., 2002; Cao et al., 2011). The results indicate that not only the size of the inclusion but also its shape and stringer formation have an impact on the corrosion behavior of steel (Wohlschlögel et al., 2014).

\section{DISCUSSION}

As shown in Figure 9A, one of the mechanisms of corrosion resistance is associated with the increased level of matrix stresses in the inclusion region, owing to the difference in the thermal coefficient values of inclusion and the matrix linear expansion, and the increased volume of the $\mathrm{MgAl}_{2} \mathrm{O}_{4} \cdot \mathrm{CaO}$ system inclusions in Steel 2 by hydration upon contact with the electrolyte. For inclusion in Steel 3 shown in Figure 9B, the acceleration of corrosion was more closely related to the dissolution of the inclusion itself, owing to the chemical activity associated with the pitting formation. The inclusion 


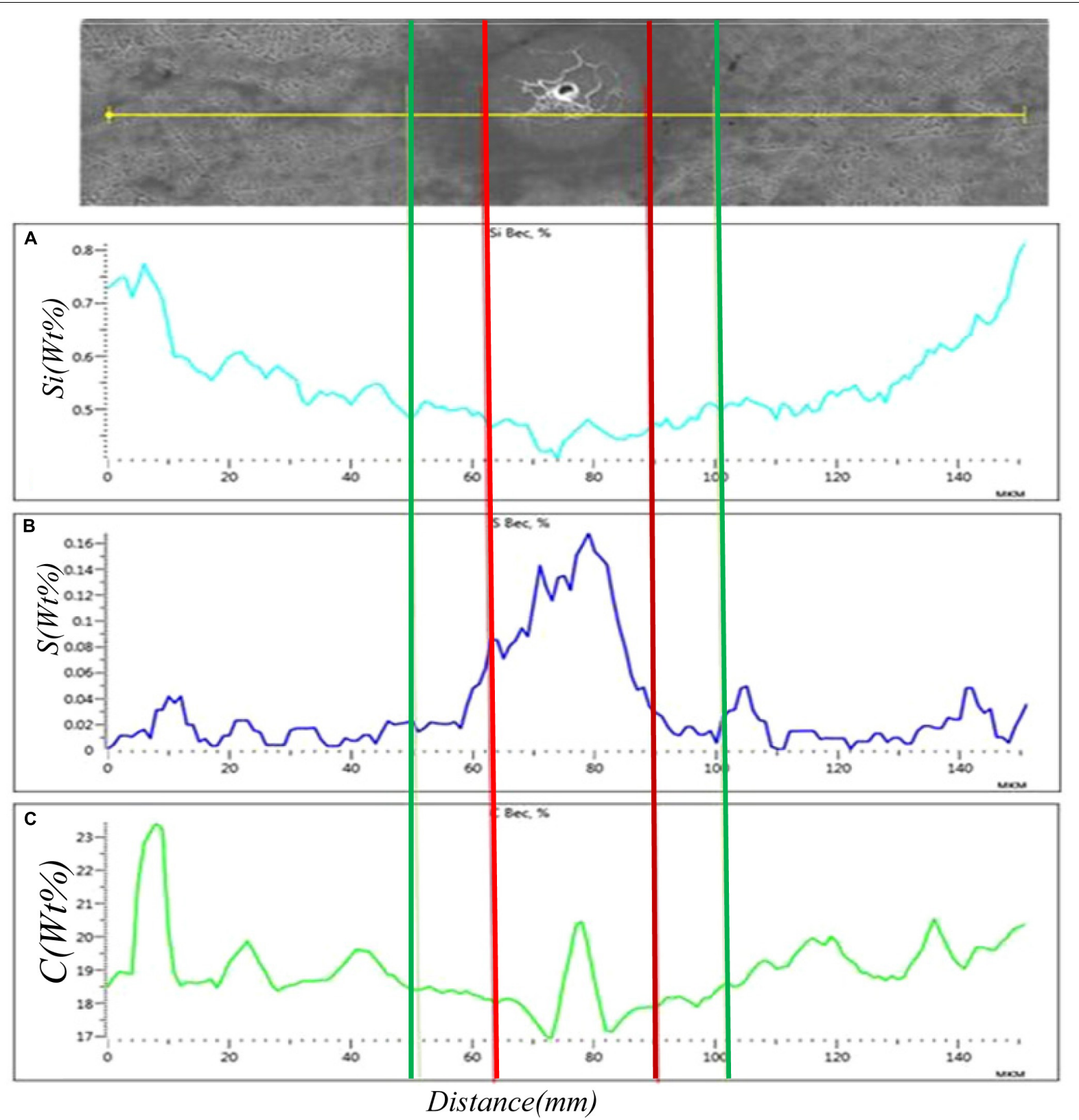

FIGURE 8 | Distribution of elements in the rift zone around an inclusion: (A) silicon, (B) sulfur, and (C) carbon. The rift region was limited by two red lines on the figure, the region of the rift together with the non-etched area was highlighted by two the green lines.

based on the Al-Mg spinel, which also contains an oxide component, resulted in increased stress level around the inclusion. The sulfide component promoted the chemical activity of the inclusion. Thus, it can be assumed that these inclusions will exhibit higher corrosion activity compared to inclusions in Steel 3 based on the amount of aluminate calcium present. With respect to inclusion, it was suggested that the activation of the matrix dissolution around the inclusion could be related to the difference in its chemical composition and the rest of the matrix; this was because of segregation and/or formation of heterogeneity of the chemical composition during the crystallization or subsequent reworking of the steel (Shibaeva et al., 2014; Wu et al., 2014; Costa e Silva, 2019).

As shown in Figures 6, 9B, approximately $80 \%$ of the $\mathrm{Zr}$ Ti oxide particles in deoxidized Steel 3 are less than $5 \mu \mathrm{m}$ in size, while only $50 \%$ of the oxide particles in $\mathrm{Al}$ deoxidized Steel 1 are smaller than $5 \mu \mathrm{m}$ in size. Therefore, compared with the Al deoxidized steel, more fine inclusions exist in the $\mathrm{Zr}$-Ti-deoxidized steel. $\mathrm{MnS}$ and $\mathrm{ZrO}_{2}$ have the same lattice 

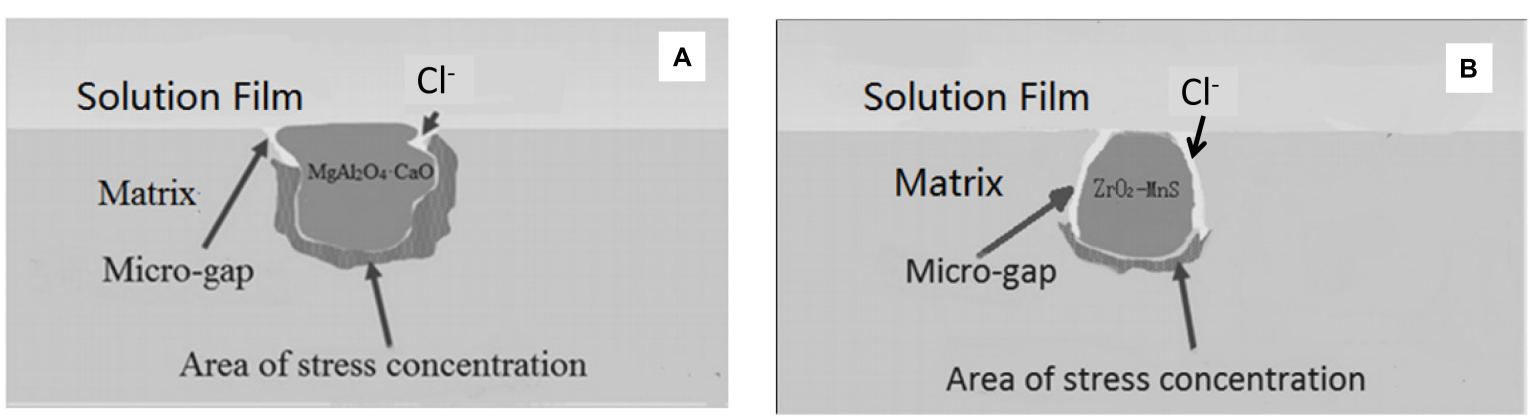

FIGURE 9 | Schematic representation of the pit initiation induced by micro-meter inclusions in the steels, namely (A) Steels 1 and 2 , and (B) Steel 3.

constants, resulting in good lattice matching. This reduces the interface energy between the two so that there is good adhesion between the grains at different interfaces. $\mathrm{ZrO}_{2}$ are anionic vacancy oxides, but the crystal structure characteristics of $\mathrm{ZrO}_{2}-$ $\mathrm{MnS}$ allow it to be readily doped. The $\mathrm{Mn}$ ionic radius is similar to the $\mathrm{Zr}$ ionic radius, and it can thus be mixed into the $\mathrm{ZrO}_{2}$ to obtain structurally stable doped oxides. $\mathrm{Al}_{2} \mathrm{O}_{3}$ does not easily become a vacancy oxide; moreover, the crystal structure of its corundum is relatively stable, which is not conducive to doping. When $\mathrm{Zr}$-Ti-deoxidization is used, finely distributed $\mathrm{Zr}$ Ti composite oxides are formed in the steel, which provides nucleation particles for $\mathrm{MnS}$ precipitation, spheroidizing the $\mathrm{MnS}$ and forming a uniform, fine, and diffuse distribution in the steel (Liu et al., 2018).

\section{CONCLUSION}

The main results of this study are summarized as follows:

1. According to the results of the metallographic analysis, the main structure of the steel plate is ferrite and pearlite, and the average grain size is $5.8 \mu \mathrm{m}$. The microhardness of the sample has a stable value (170-200 HV) and the impact energy of $\mathrm{Zr}$-Ti-deoxidized steel at a test temperature of $-120^{\circ} \mathrm{C}$ is $308 \mathrm{~J}$, which is significantly greater than that of Al-deoxidized steel.

2. Approximately $80 \%$ of the $\mathrm{Zr}-\mathrm{Ti}$ oxide particles in deoxidized steel are less than $5 \mu \mathrm{m}$ in size, while only $50 \%$ of the oxide particles in $\mathrm{Al}$ deoxidized steel are smaller than $5 \mu \mathrm{m}$ in size. The Al-deoxidized steel of Steel 1 has a maximum contamination level of $8.3 \mathrm{incl} . / \mathrm{mm}^{2}$. In contrast, Steel 2 has the lowest inclusion contamination, with the composition of its oxide component characterized by a high ratio and low calcium content. The micro crevices and high-dislocation-density region around the inclusions can easily induce localized corrosion. The high ratio of $\mathrm{Al}$ to $\mathrm{Mg}$ in the oxide component of the inclusion and the absence of its modification with Ca could result in a higher corrosive activity for the inclusions.

3. $\mathrm{Zr}$-Ti-deoxidized steel has a current density of $5.78 \mathrm{~mA} / \mathrm{cm}^{2}$, which is the lowest of the three steels.
The average corrosion rate of the $\mathrm{Zr}$-Ti-deoxidized steel is $1.44 \mathrm{~mm} / \mathrm{h}$, which is lower than that of the Al-deoxidized steel. Thus, the $\mathrm{Zr}$-Ti-deoxidized steel exhibits a better seawater corrosion resistance.

4. The inclusion based on the $\mathrm{Al}-\mathrm{Mg}$ spinel, which also contains an oxide component, resulted in an increased stress level around the inclusion. When steel was deoxidized with $\mathrm{Zr}-\mathrm{Ti}$, small $\mathrm{Zr}$-Ti complex oxides were formed and distributed in the steel, thereby providing nucleation particles for the precipitation of $\mathrm{MnS}$, which spheroidized and homogenized them. The region of the rift is characterized by an increased sulfur content of $0.16 \%$, arising from the precipitation of the reaction products formed due to the dissolution of the sulfide part of the inclusion in the region immediately adjacent to the inclusion.

\section{DATA AVAILABILITY STATEMENT}

The original contributions presented in the study are included in the article/supplementary material, further inquiries can be directed to the corresponding author.

\section{AUTHOR CONTRIBUTIONS}

ML, HW, and YS contributed to the design and implementation of the research, analysis of the results, and writing of the manuscript. All authors contributed to the article and approved the submitted version.

\section{ACKNOWLEDGMENTS}

The authors thank Hongbiao Dong for providing language help and for assistance during the experiments. The authors also thank NISCO Company for providing the test equipment. 


\section{REFERENCES}

Alfred, R. L., Myland, J. C., and Oldham, K. (2002). Corrosion current densities at a disk-shaped inclusion. J. Solid State Electrochem. 6, 172-182. doi: 10.1007/ s100080100218

Cai, G., and Li, C. (2015). Effects of Ce on inclusions, microstructure, mechanical properties, and corrosion behavior of AISI 202 stainless steel. J. Mater. Eng. Perform. 24, 3989-4009. doi: 10.1007/s11665-015-1651-6

Cao, G. I., Li, G.-M., Chen, S., Chang, W.-S., and Chen, X.-Q. (2011). Effects of deoxidizing degree on the pitting corrosion behavior of carbon and manganese steels. Int. J. Miner. Metall. Mater. 18, 169-177. doi: 10.1007/s12613-011-0418-9

Chen, A.-H., Xu, J.-Q., Li, R., and Li, H.-L. (2012). Corrosion resistance of high performance weathering steel for bridge building applications. J. Iron Steel Res. 19, 59-63. doi: 10.1016/S1006-706X(12)60128-9

Costa e Silva, A. L. V. (2019). The effects of non-metallic inclusions on properties relevant to the performance of steel in structural and mechanical applications. J. Mater. Res. Technol. 8, 2408-2422. doi: 10.1016/j.jmrt.2019.01.009

Li, Y., Wan, X. L., Lu, W. Y., Shirzadi, A. A., Isayev, O., Hress, O., et al. (2016). Effect of $\mathrm{Zr}$-Ti combined deoxidation on the microstructure and mechanical properties of high-strength low-alloy steels. Mater. Sci. Eng. A 659, 179-187. doi: 10.1016/j.msea.2016.02.035

Liu, C., Revilla, R., Zhang, D., Liu, Z., Lutz, A., Zhang, F., et al. (2018). Role of $\mathrm{Al} 2 \mathrm{O} 3$ inclusions on the localized corrosion of Q460NH weathering steel in marine environment. Corros. Sci. 138, 96-104. doi: 10.1016/j.corsci.2018.04.007

Luo, K., and Bai, B. (2011). Mechanical properties and corrosion-abrasion wear behavior of low-alloy MnSiCrB cast steels containing Cu. Metall. Mater. Trans. A 42, 181-191. doi: 10.1007/s11661-010-0494-x

Panin, S. V., Maruschak, P. O., Vlasov, I. V., Syromyatnikova, A. S., Bolshakov, M. A., Berto, F., et al. (2017). Effect of operating degradation in arctic conditions on physical and mechanical properties of 09Mn2Si pipeline steel. Procedia Eng. 178, 587-603. doi: 10.1016/j.proeng.2017.01.117

Panin, S. V., Vlasov, I. V., Maruschak, P. O., Eremin, A. V., Berto, F., Syromyatnikova, A. S., et al. (2019). Influence of long-term cold climate operation on structure, fatigue durability and impact toughness of $09 \mathrm{Mn} 2 \mathrm{Si}$ pipe steel. Eng. Fail. Anal. 102, 87-101. doi: 10.1016/j.engfailanal.2019.04.036

Rodionova, I. G., Baklanova, O. N., Filippov, G. A., Reformatskaya, I. I., Podobaev, A. N., Zinchenko, S. D., et al. (2005a). The role of nonmetallic inclusions in accelerating the local corrosion of metal products made of plain-carbon and low-alloy steels. Metall 49, 124-130. doi: 10.1007/s11015-005-0065-3

Rodionova, I. G., Baklanova, O. N., Filippov, G. A., Zinchenko, S. D., Filatov, M. V., Efimov, S. V., et al. (2005b). The influence of the role of non-metallic inclusions of a special type on the acceleration of the local corrosion processes in oilfield pipes. Stal 1, 86-88.

Rodionova, I. G., Baklanova, O. N., and Zaytsev, A. I. (2004). The role of nonmetallic inclusions in accelerating the processes of local corrosion of oilfield pipelines made of carbonaceous and low-alloy steels. Metals 5, 3-18.
Shi, W., Yang, S., Dong, A., and Li, J. (2018). Understanding the corrosion mechanism of spring steel induced by mns inclusions with different sizes. Min. Meta. Mater. Soc. JOM 70, 2513-2522. doi: 10.1007/s11837-0183026-6

Shibaeva, T., Laurinavichyute, K., Tsirlina, G., Arsenkin, A., and Grigorovich, K. (2014). The effect of microstructure and non-metallic inclusions on corrosion behavior of low carbon steel in chloride containing solutions. Corros. Sci. 80, 299-308. doi: 10.1016/j.corsci.2013.11.038

Sun, F., Li, X., Zhang, F., Cheng, X., Zhou, C., Wu, N., et al. (2013). Corrosion mechanism of corrosion-resistant steel developed for bottom plate of cargo oil tanks. Acta Metall. Sin. (Engl. Lett.) 26, 257-264. doi: 10.1007/s40195-0120231-0

Wei, W. Z., Wu, K. M., Zang, X., Liu, J., Qiu, P., and Cheng, L. (2020). In-situ characterization of initial marine corrosion induced by rare-earth elements modified inclusions in Zr-Ti deoxidized low-alloy steels. J. Mater. Res. Technol. 9, 1412-1424. doi: 10.1016/j.jmrt.2019.11.080

Wohlschlögel, M., Steegmüller, R., and Schüßler, A. (2014). Effect of inclusion size and distribution on the corrosion behavior of medical-device grade nitinol tubing. J. Mater. Eng. Perform. 23, 2635-2640. doi: 10.1007/s11665-014-0996-6

Wu, H., Liang, J., Tang, D., Liu, X., Zhang, P., and Yue, Y. (2014). Influence of inclusion on corrosion behavior of E36 grade low-alloy steel in cargo oil tank bottom plate environment. J. Iron Steel Res. Int. 21, 1016-1021. doi: 10.1016/ S1006-706X(14)60177-1

Zhang, X., Wei, W., Cheng, L., Liu, J., Wu, K., and Liu, M. (2019). Effects of niobium and rare earth elements on microstructure and initial marine corrosion behavior of low-alloy steels. Appl. Surf. Sci. 475, 83-93. doi: 10.1016/ j.apsusc.2018.12.243

Zinchenko, S. D., Lamukhin, A. M., Filatov, M. V., Efimov, S. V., Rodionova, I. G., Zaitsev, A. I., et al. (2005). Development of recommendations on making tube steels produced at the severstal combine cleaner with respect to corrosionactive nonmetallic inclusions. Metall 4, 131-137. doi: 10.1007/s11015-0050066-2

Conflict of Interest: ML was employed by the company of Nanjing Iron and Steel Co., Ltd.

The remaining authors declare that the research was conducted in the absence of any commercial or financial relationships that could be construed as a potential conflict of interest.

Copyright (C) $2021 \mathrm{Li}, \mathrm{Wu}$ and Sun. This is an open-access article distributed under the terms of the Creative Commons Attribution License (CC BY). The use, distribution or reproduction in other forums is permitted, provided the original author(s) and the copyright owner(s) are credited and that the original publication in this journal is cited, in accordance with accepted academic practice. No use, distribution or reproduction is permitted which does not comply with these terms. 